\title{
Validação das relações dos aminoácidos metionina, treonina, triptofano e valina com a lisina digestível na proteína ideal em rações para porcas em lactação
}

\section{Douglas Haese ${ }^{1}$, Juarez Lopes Donzele ${ }^{2}$, Rita Flávia Miranda de Oliveira ${ }^{2}$, João Luís Kill ${ }^{1}$, Márvio Lobão Teixeira de Abreu ${ }^{3}$, Alysson Saraiva ${ }^{4}$, Francisco Carlos de Oliveira Silva ${ }^{5}$, Débora Del Puppo6}

\author{
1 Programa de Mestrado em Ciência Animal - UVV. \\ 2 Departamento de Zootecnia - UFV. \\ 3 Departamento de Veterinária - UFPI. \\ ${ }^{4}$ Programa de Pós-graduação em Zootecnia/Departamento de Zootecnia-UFV. \\ 5 EPAMIG. \\ ${ }^{6}$ Medicina veterinária - UVV.
}

RESUMO - Com o objetivo de validar as relações de aminoácidos digestíveis com a lisina digestível propostas com base no conceito da proteína ideal, foi realizado um experimento com 120 matrizes suínas em lactação, distribuídas em delineamento em blocos, composto de seis dietas, 20 blocos e uma matriz por unidade experimental. As dietas foram formuladas a partir de uma dieta-referência - contendo 19,5\% de proteína bruta (PB) e 0,95\% de lisina digestível suplementada com metionina, treonina, triptofano e/ou valina digestíveis para atingir as relações com a lisina digestível determinadas com base na proteína ideal. As dietas não influenciaram a perda e a variação de peso, a espessura e a variação da espessura de toucinho, a proteína e a variação de proteína corporal, a gordura e a variação de gordura corporal nem alteraram o intervalo desmame-estro ou a produção de leite das porcas. As relações dos aminoácidos metionina + cistina, treonina, triptofano e valina digestíveis com a lisina digestível propostas com base na proteína ideal atendem às exigências de porcas em lactação para melhores desempenhos produtivo e reprodutivo.

Palavras-chave: estro, gordura, leitões, peso, proteína, ração

\section{Validation of the relationships of methionine, threonine, tryptophan and valine amino acids with the digestible lysine in the ideal protein in feedings for lactating sows}

\begin{abstract}
This experiment aimed at validating the relationship between digestible amino acids with the digestible lysine proposed on the basis of the ideal protein concept. This experiment used 120 lactating sows distributed in a complete randomized block design with six treatments and 20 repetitions and one sow per experimental unity. The diets were formulated based on a reference diet - which contained $19.5 \%$ of crude protein (CP) and $0.95 \%$ of digestible lysine supplemented with digestible methionine, threonine, tryptophan and/or valine to meet the ideal protein based determined relationships with digestible lysine. The diets did not change weight loss and variation, thickness and thickness variation of backfat, protein and body protein variation, fat and body fat variation, neither they changed the weaning-estrus interval or milk production of the sows. The relationships between metionine + cistine, threonine, tryptophan, and valine digestible amino acids with digestible lysine based proposed on ideal protein meet the requirements of lactating sows for better reproductive and productive performances.
\end{abstract}

Key Words: estrus, fat, piglets, protein, ration, weight

\section{Introdução}

Atualmente, as matrizes suínas são mais magras, mais produtivas e possuem menor capacidade de consumo voluntário de ração. A redução no consumo tem reflexos diretos sobre o desempenho reprodutivo da matriz e a taxa de sobrevivência e de crescimento da leitegada, uma vez que o leite normalmente é a principal fonte de alimento disponível para o leitão durante a lactação (Jones \& Stahly, 1999a). Assim, quando o consumo de aminoácidos e de energia não é suficiente para atender as exigências para a produção de leite, as porcas mobilizam proteína e gordura dos tecidos 
corporais com o objetivo de suprir as exigências de aminoácidos e energia para sustentar esta produção (Mullan \& Willians, 1990).

Segundo Clowes et al. (2003), a perda de 10 a $15 \%$ do peso corporal durante a lactação tem como consequências a redução da produção de leite e do desempenho reprodutivo subsequente. Essa situação é mais evidente em matrizes de primeiro parto que, por ainda se encontrarem em fase de crescimento, têm suas exigências nutricionais aumentadas. O resultado pode ser uma elevada taxa de descarte de matrizes antes do terceiro parto, comprometendo o rendimento econômico do sistema produtivo (Abreu et al., 2005). Assim, para otimizar a produção de leite e minimizar a mobilização corporal das porcas, as rações devem ser formuladas para máxima eficiência de aproveitamento dos nutrientes. Dessa forma, o conhecimento dos nutrientes que são limitantes é essencial para se alcançar tal objetivo.

Este trabalho foi conduzido para validar as relações dos aminoácidos metionina + cistina (54\%), treonina (64\%), triptofano (19\%) e valina (78\%) digestíveis com a lisina digestível para porcas em lactação, valendo-se do conceito da proteína ideal, proposto por Rostagno et al. (2005), com base nos desempenhos produtivo e reprodutivo dos animais.

\section{Material e Métodos}

Foram utilizadas 120 matrizes suínas em lactação, distribuídas em delineamento experimental de blocos ao acaso, contendo seis dietas, 20 repetições (bloco) e um animal por unidade experimental.

Para a validação da relação dos aminoácidos estudados com a lisina digestível, foram utilizadas seis dietas experimentais, assim constituídas: 19,5\% de proteína bruta (PB) e 0,95\% de lisina digestível (LD), sem suplementação de aminoácidos industriais; $16,8 \%$ de PB e 0,95\% de lisina digestível, suplementada com aminoácidos para atingir os mesmos níveis de aminoácidos da dieta-referência, exceto metionina + cistina; $16,8 \%$ de $\mathrm{PB}$ e $0,95 \%$ de $\mathrm{LD}$, suplementada com aminoácidos para atingir os mesmos níveis de aminoácidos da dieta-referência, exceto treonina; 16,8\% de PB e 0,95\% de LD, suplementada com aminoácidos para atingir os mesmos níveis de aminoácidos da dietareferência, exceto triptofano; $16,8 \%$ de PB e $0,95 \%$ de lisina digestível, suplementada com aminoácidos para atingir os mesmos níveis da dieta-referência, exceto valina; $16,8 \%$ de PB e 0,95\% de lisina digestível, suplementada com metionina, treonina, triptofano e valina digestíveis para atingir as relações com a lisina digestível com base na proteína ideal.
Os critérios utilizados para distribuição dos animais foram o peso pós-parto e a ordem de parto. Os aminoácidos industriais foram incorporados às dietas, em substituição ao amido.

As dietas experimentais foram preparadas à base de milho, farelo de soja, casquinha de soja e suplementadas com minerais e vitaminas (Tabela 1). O fornecimento destas aos animais foi feito de maneira controlada, na quantidade de $6,0 \mathrm{~kg}$, divididas em três refeições diárias. A água foi fornecida à vontade.

A temperatura, no interior do galpão, foi aferida por meio de termômetros de máxima e mínima, sendo realizada diariamente às $8 \mathrm{~h}$, durante todo o período experimental.

As porcas foram encaminhadas à maternidade cinco dias antes da data prevista do parto e pesadas 24 horas após o parto, sendo a espessura de toucinho medida no momento da pesagem, por meio de ultrassom. Foram realizadas duas medidas a 6,5 centímetros da linha dorsal do animal à direita e à esquerda, à altura da décima costela (P2), tomando-se como resultado as médias das avaliações dos dois lados. Ao final do período de lactação, as porcas foram novamente pesadas e a espessura de toucinho, mensurada.

As leitegadas foram pesadas após o nascimento e equalizadas em 11 ou 12 leitões/fêmea, até 72 horas pósparto. O corte de dentes e de cauda, a cura do umbigo e a marcação dos leitões foram realizados até 24 horas após o nascimento. Após o desmame, os leitões foram novamente pesados e encaminhados para o setor de creche e as porcas, para o setor de gestação, onde foram alojadas em gaiolas individuais e alimentadas com 3,0 kg de ração de lactação/ fêmea/dia, distribuídas em duas refeições diárias.

No período do desmame à cobertura subsequente, foi realizado o acompanhamento do retorno ao estro, todos os dias, pela manhã, levando-se o cachaço à baia da porca. Foram consideradas em estro as porcas que permaneceram imóveis à monta (reflexo de tolerância ao macho - RTM positivo).

Foram avaliadas as seguintes variáveis: consumo de ração; consumo de lisina digestível; variação do peso corporal, da espessura de toucinho; da proteína corporal e da gordura corporal; estimativa da produção de leite; dias de intervalo desmame-estro; peso de leitões ao nascimento e à desmama, e ganho de peso do leitão e da leitegada. Todas as variáveis foram analisadas pelo Sistema de Análises Estatísticas e Genéticas (SAEG), desenvolvido pela Universidade Federal de Viçosa (1999). Na comparação das médias, utilizou-se o teste "Student Newman Keuls”, a 5\% de probabilidade. 
Tabela 1 - Composições das dietas experimentais

\begin{tabular}{|c|c|c|c|c|c|c|}
\hline Ingrediente (\%) & \multicolumn{6}{|c|}{ Relação aminoácido:lisina digestível ${ }^{1}$} \\
\hline Farelo de soja $45 \%$ & 33,256 & 25,130 & 25,130 & 25,130 & 25,130 & 25,130 \\
\hline Sebo bovino & 5,839 & 5,580 & 5,580 & 5,580 & 5,580 & 5,580 \\
\hline Soja casquinha & 4,000 & 4,000 & 4,000 & 4,000 & 4,000 & 4,000 \\
\hline Fosfato bicálcico & 1,769 & 1,817 & 1,817 & 1,817 & 1,817 & 1,817 \\
\hline Calcário calcítico & 0,612 & 0,642 & 0,642 & 0,642 & 0,642 & 0,642 \\
\hline Sal comum & 0,198 & 0,206 & 0,206 & 0,206 & 0,206 & 0,206 \\
\hline Premix mineral $^{2}$ & 0,120 & 0,120 & 0,120 & 0,120 & 0,120 & 0,120 \\
\hline Premix vitamínico ${ }^{3}$ & 0,350 & 0,350 & 0,350 & 0,350 & 0,350 & 0,350 \\
\hline Bacitracina de zinco & 0,035 & 0,035 & 0,035 & 0,035 & 0,035 & 0,035 \\
\hline L-treonina & 0,000 & 0,105 & 0,067 & 0,105 & 0,105 & 0,067 \\
\hline L-triptofano & 0,000 & 0,041 & 0,041 & 0,005 & 0,041 & 0,005 \\
\hline L-valina & 0,000 & 0,130 & 0,130 & 0,130 & 0,050 & 0,050 \\
\hline \multicolumn{7}{|l|}{ Composição nutricional } \\
\hline Energia digestível (kcal/kg) & 3.590 & 3.590 & 3.590 & 3.590 & 3.590 & 3.590 \\
\hline Energia metabolizável (kcal/kg) & 3.400 & 3.400 & 3.400 & 3.400 & 3.400 & 3.400 \\
\hline Proteína bruta (\%) & 19,50 & 16,80 & 16,80 & 16,80 & 16,80 & 16,80 \\
\hline Lisina digestível (\%) & 0,950 & 0,950 & 0,950 & 0,950 & 0,950 & 0,950 \\
\hline Metionina + cistina digestível (\%) & 0,546 & 0,513 & 0,546 & 0,546 & 0,546 & 0,513 \\
\hline Treonina digestível (\%) & 0,646 & 0,646 & 0,608 & 0,646 & 0,646 & 0,608 \\
\hline Triptofano digestível (\%) & 0,215 & 0,215 & 0,215 & 0,181 & 0,215 & 0,181 \\
\hline Valina digestível (\%) & 0,819 & 0,819 & 0,819 & 0,819 & 0,741 & 0,741 \\
\hline
\end{tabular}

${ }^{1}$ Relação aminoácido/lisina baseada na recomendação de Rostagno et al. (2005).

2 Composição por kg do produto: Fe - 180 g; Cu - 20 g; Co - 4 g; Mn - 80 g; Zn - 140 g; I - 4 g; excipiente q.s. p. - 1.000 g.

${ }^{3}$ Composição por kg do produto: vit. A - 12.000 .000 UI; vit. D3 - 1.500 .000 UI; vit. E - 8.000 UI; vit. K3 - 4 g; vit. B2 - 4 g; vit. B6 - 5 g; vit. B12 - 30.000 mg; ácido nicotínico - 40 g; ácido pantotênico - 20 g; bacitracina de zinco - 10 g; antioxidante - 30 g; e excipiente q.s.p. - 1.000 g.

\section{Resultados e Discussão}

As médias das temperaturas observadas no termômetro de máxima e mínima foram de $26,8 \pm 3,46$ e $16,7 \pm 2,86^{\circ} \mathrm{C}$, respectivamente. Considerando que a zona de termoneutralidade para porcas em lactação, segundo Black et al. (1993) e De Bragança et al. (1998), está caracterizada por temperaturas entre 16 e $22^{\circ} \mathrm{C}$, é provável que, baseado na variação de temperatura ocorrida durante o período experimental, as porcas foram submetidas a períodos de estresse por calor.

Não houve efeito $(\mathrm{P}>0,05)$ das dietas sobre a média de consumo de ração, que foi de $5,69 \mathrm{~kg} /$ dia (Tabela 2 ), o que está coerente com o fato de se ter fixado a quantidade de ração oferecida diariamente aos animais. Embora a quantidade de ração oferecida às porcas tenha sido a mesma nas diferentes dietas, os animais não alcançaram o consumo total pré-determinado de 6,0 kg de ração/dia.
Tabela 2 - Consumo médio diário de ração e de lisina digestível em fêmeas suínas durante a lactação

\begin{tabular}{lcc}
\hline $\begin{array}{l}\text { Relação aminoácido: } \\
\text { lisina digestível }\end{array}$ & \multicolumn{2}{c}{${ }^{1}$} \\
\cline { 2 - 3 } & Ração (kg/dia) & Lisina (g/dia) \\
\hline Acima da relação & 5,59 & 53,1 \\
Metionina + cistina (54\%) & 5,71 & 54,2 \\
Treonina (64\%) & 5,73 & 54,4 \\
Triptofano (19\%) & 5,80 & 55,1 \\
Valina (78\%) & 5,67 & 53,9 \\
Na relação & 5,61 & 53,3 \\
Média & 5,69 & 54,0 \\
CV (\%) & 6,73 & 6,73 \\
\hline
\end{tabular}

${ }^{1}$ Relação aminoácido/lisina baseada na recomendação de Rostagno et al. (2005).

O estresse devido ao parto, na primeira semana, e do calor, aos quais as porcas foram submetidas durante determinados períodos do experimento, além da utilização de porcas primíparas, que normalmente possuem um baixo consumo de ração, possivelmente estão entre os fatores 
que contribuíram para que o consumo diário de ração não fosse atingido.

O consumo de lisina digestível também não variou $(\mathrm{P}>0,05)$ entre os animais que receberam as diferentes dietas, o que é justificado pelo fato destas serem isolisínicas e o consumo total das dietas, pelas porcas, também não ter variado.

Touchette et al. (1998) estimaram a necessidade de lisina digestível pela matriz suína para um bom crescimento de leitegada em 27 g/dia, enquanto a necessidade diária para minimizar a mobilização de proteína corporal seria de 46,5 g/dia. Segundo Tokach et al. (1992), a exigência de lisina para minimizar a perda de massa muscular durante a lactação e melhorar o desempenho reprodutivo subsequente é mais alta que a exigência para produção de leite e desenvolvimento da leitegada.

Considerando os relatos desses autores, pode-se inferir que o consumo de 53,1 g/dia de lisina, observado nos animais tratados com a dieta contendo 19,5\% PB sem suplementação de aminoácidos industriais, foi suficiente para otimizar o crescimento da leitegada e evitar excessiva mobilização proteica.

Não se observou efeito $(\mathrm{P}>0,05)$ das dietas sobre a perda de peso das porcas, que correspondeu, em média, a
4,35 kg (Tabela 3). Em razão direta desse resultado, as dietas avaliadas não influenciaram $(\mathrm{P}>0,05)$ a variação de peso corporal das porcas, que teve, em média, redução de $1,80 \%$.

De forma semelhante, Jones \& Stahly (1999a) e Clowes et al. (2003), avaliando, respectivamente, níveis de aminoácidos e proteína para porcas durante a lactação, não constataram efeito das dietas sobre a variação de peso dos animais com o aumento dos níveis de aminoácidos e de proteína.

Por outro lado, Richert et al. (1997), Dourmad et al. (1998) e Jones \& Stahly (1999a) constataram maior perda de peso das porcas ao final da lactação, quando estas consumiram rações com baixos níveis de aminoácidos. De acordo com os autores, o baixo consumo de proteína e aminoácidos durante a lactação aumenta a mobilização de proteína corporal.

Não houve efeito $(\mathrm{P}>0,05)$ das dietas consumidas sobre a variação da espessura de toucinho $\left(\mathrm{ET}_{\mathrm{P}}\right)$ das porcas, $\mathrm{o}$ que está consistente com o fato de não ter havido efeito $(\mathrm{P}>0,05)$ das dietas sobre a variação de gordura corporal.

Resultados semelhantes foram observados por Richert et al. (1997), Dourmad et al. (1998), Touchette et al. (1998), Cota et al. (2003) e Oliveira et al. (2008), que avaliaram níveis

Tabela 3 - Composição corporal, período e produção de leite de porcas em função das diferentes dietas consumidas

\begin{tabular}{|c|c|c|c|c|c|c|c|}
\hline \multirow[t]{2}{*}{ Variável } & \multicolumn{6}{|c|}{ Relação aminoácido:lisina digestível ${ }^{1}$} & \multirow{2}{*}{$\begin{array}{l}\text { CV } \\
(\%)\end{array}$} \\
\hline & $\begin{array}{l}\text { Acima da } \\
\text { relação }\end{array}$ & $\begin{array}{l}\text { Metionina }+ \\
\text { cistina }(54 \%)\end{array}$ & $\begin{array}{c}\text { Treonina } \\
\text { (64\%) }\end{array}$ & $\begin{array}{c}\text { Triptofano } \\
(19 \%)\end{array}$ & $\begin{array}{l}\text { Valina } \\
(78 \%)\end{array}$ & Na relação & \\
\hline Número de porcas & 20 & 20 & 20 & 20 & 20 & 20 & \\
\hline \multicolumn{8}{|l|}{ Peso da porca } \\
\hline Pós-parto (kg) & 243,55 & 241,89 & 239,56 & 243,11 & 242,33 & 242,56 & 16,04 \\
\hline À desmama (kg) & 239,78 & 235,78 & 236,28 & 237,72 & 239,67 & 237,67 & 16,03 \\
\hline Perda de peso (kg) & 3,77 & 6,11 & 3,28 & 5,39 & 2,66 & 4,89 & 135,05 \\
\hline Variação de peso (\%) & $-1,55$ & $-2,53$ & $-1,37$ & $-2,22$ & $-1,10$ & $-2,02$ & 147,55 \\
\hline \multicolumn{8}{|l|}{ Espessura de toucinho $\left(\mathrm{ET} \mathrm{P}_{2}\right)$} \\
\hline Pós-parto (mm) & 14,36 & 15,33 & 16,58 & 13,79 & 14,42 & 14,43 & 18,9 \\
\hline À desmama (mm) & 13,71 & 14,50 & 15,64 & 13,01 & 13,93 & 13,54 & 19,38 \\
\hline Variação da espessura de toucinho (mm) & $-0,65$ & $-0,83$ & $-0,94$ & $-0,78$ & $-0,49$ & $-0,89$ & 180,50 \\
\hline \multicolumn{8}{|l|}{ Proteína corporal $(\mathrm{kg})^{2}$} \\
\hline Pós-parto & 40,82 & 40,29 & 39,57 & 40,86 & 40,57 & 40,61 & 16,20 \\
\hline À desmama & 40,24 & 39,31 & 39,15 & 40,00 & 40,17 & 39,88 & 16,18 \\
\hline Variação de proteína corporal (\%) & $-1,40$ & $-2,43$ & $-1,05$ & $-2,09$ & $-0,98$ & $-1,81$ & 196,48 \\
\hline \multicolumn{8}{|l|}{ Gordura corporal $(\mathrm{kg})^{3}$} \\
\hline Pós-parto & 52,29 & 53,39 & 54,78 & 51,34 & 52,12 & 52,18 & 18,63 \\
\hline À desmama & 50,52 & 50,86 & 52,68 & 49,04 & 50,83 & 49,82 & 18,74 \\
\hline Variação de gordura corporal (\%) & $-3,38$ & $-4,73$ & $-3,83$ & $-4,48$ & $-2,48$ & $-4,53$ & 141,82 \\
\hline Período de lactação (dias) & 18,67 & 18,67 & 18,39 & 18,61 & 18,22 & 17,89 & 19,0 \\
\hline Intervalo desmame-estro (dias) & 4,56 & 4,57 & 4,54 & 5,00 & 4,50 & 3,81 & 4,63 \\
\hline Produção de leite $(\mathrm{kg} / \text { porca/dia })^{4}$ & 10,41 & 10,42 & 10,61 & 10,79 & 10,19 & 10,99 & 10,99 \\
\hline
\end{tabular}

${ }^{1}$ Relação aminoácido/lisina com base na recomendação de Rostagno et al. (2005).

${ }^{2}$ Conteúdo de proteína corporal $(\mathrm{kg})$ considerando peso e ET $\mathrm{P}_{2}$ da porca pós-parto e à desmama $=-2,3+(0,19 \times$ peso corporal, $\mathrm{kg})-\left(0,22 \times \mathrm{ET} \mathrm{P}_{2}\right.$, mm) .

Fonte: Whittemore \& Yang (1989).

${ }^{3}$ Conteúdo de gordura corporal $(\mathrm{kg})$ considerando peso e ET P2 da porca pós-parto e à desmama $=-20,4+(0,21 \times$ peso corporal, $\mathrm{kg})+\left(1,5 \times\right.$ ET $\mathrm{P}_{2}$, mm $)$. Fonte: Whittemore \& Yang (1989)

${ }^{4}$ Produção de leite $(\mathrm{g} / \mathrm{dia})=7+[2,5 \times$ ganho de peso médio do leitão $(\mathrm{g})]+[80,2 \times$ peso inicial do leitão $(\mathrm{kg})] \times$ número de leitões. Fonte: Noblet \& Etienne $(1989)$. 
de aminoácidos para porcas em lactação e também não verificaram variação na espessura de toucinho dos animais na lactação. Por outro lado, Clowes et al. (2003) verificaram aumento na mobilização de gordura corporal com a redução dos níveis de proteína na ração. Assim, os dados obtidos diferem da afirmação de Jones \& Stahly (1999b) de que a variação na espessura de toucinho não é uma característica sensível para avaliar a condição corporal da porca.

Não houve alteração $(\mathrm{P}>0,05)$ no número de dias para retorno das porcas ao estro após o desmame. Considerando o relato de Clowes et al. (2003) de que porcas em lactação podem perder de 9 a $12 \%$ da massa proteica corporal sem comprometimento de seu desempenho reprodutivo, o baixo valor médio de 4,50 dias para o retorno das porcas ao estro após o desmame está coerente com as reduzidas mobilizações de proteína $(1,63 \%)$ e gordura $(3,91 \%)$ observadas nos animais dos diferentes tratamentos.

De forma semelhante, Thaker \& Bilkei (2005), avaliando a implicação da perda de peso corporal sobre o desempenho reprodutivo de porcas em lactação, constataram que, quando a redução de peso foi menor do que $10 \%$, esta não teve influência sobre o retorno ao estro. O resultado obtido está coerente com os dados de King \& Dunkin (1986), os quais, estudando o efeito da nutrição sobre o desempenho reprodutivo, observaram que perdas de peso superior a $10 \%$ durante a lactação reduziram a produção de leite e comprometeram o desempenho reprodutivo subsequente.

De acordo com King (1987), os efeitos da perda de massa proteica corporal são mais importantes no intervalo desmamecio do que a perda de gordura corporal. Segundo Clowes et al. (2003), a mobilização de proteína corporal durante a lactação reduz a quantidade de folículos viáveis no ovário ao desmame e, consequentemente, diminui o número de leitões no parto subsequente. Segundo os mesmos autores, a queda na viabilidade dos folículos pode ser causada pela menor concentração do IGF-1 no líquido folicular.

Não foi observado efeito $(\mathrm{P}>0,05)$ das dietas sobre a produção de leite calculada (10,5 kg/dia) pelas porcas. Os resultados observados estão consistentes com os padrões de ganho de peso dos leitões e da leitegada verificados nesse estudo entre os tratamentos, uma vez que o crescimento da leitegada está altamente correlacionado com o nitrogênio fornecido pelo leite (Kim et al., 2001). De acordo com Johnston et al. (1993), a primeira fonte de aminoácidos para a síntese de proteína do leite é o suprimento fornecido pela dieta, mas, se tal suprimento for insuficiente, a porca utiliza suas reservas orgânicas de proteína para fornecer os aminoácidos necessários para a produção de leite. Assim, com base nos resultados obtidos, pode-se inferir que as relações propostas por Rostagno et al. (2005) foram suficientes para atender as exigências de porcas para ótima produção de leite e mínima mobilização corporal.

Como se utilizou o critério de equalização do tamanho da leitegada (número de leitões) após o parto, não se observou variação $(P>0,05)$ nessa variável entre as dietas estudadas (Tabela 4). A padronização da leitegada, feita neste estudo, pode ser justificada pelo fato de que o número de leitões na leitegada tem influência sobre a produção de leite e, consequentemente, sobre a exigência nutricional da porca (Kim et al., 1999).

O peso à desmama e os ganhos de peso dos leitões e da leitegada também não foram influenciados $(\mathrm{P}>0,05)$ pelas dietas.

O ganho de peso médio dos leitões durante a lactação ( $201 \mathrm{~g} / \mathrm{d}$ ) foi superior ao de $188 \mathrm{~g} / \mathrm{d}$ encontrado por Cota et al. (2003) e próximo ao valor médio de 197 g/dia obtido por

Tabela 4 - Desempenho da leitegada equalizada durante a lactação de acordo com as dietas

\begin{tabular}{|c|c|c|c|c|c|c|c|}
\hline Variável & \multicolumn{6}{|c|}{ Relação aminoácido:Lisina digestível ${ }^{1}$} & $\begin{array}{l}\text { CV } \\
(\%)\end{array}$ \\
\hline Leitões equalizados & 10,4 & 11,17 & 11,11 & 11,33 & 11,11 & 11,00 & 9,22 \\
\hline Leitões desmamados & 9,50 & 10,50 & 9,77 & 10,56 & 9,83 & 10,17 & 10,59 \\
\hline \multicolumn{8}{|l|}{ Peso dos leitões (kg): } \\
\hline Ao desmame & 5,24 & 5,22 & 5,34 & 5,41 & 5,17 & 5,53 & 16,57 \\
\hline Ganho de peso (kg) & 3,69 & 3,63 & 3,74 & 3,75 & 3,57 & 3,84 & 17,04 \\
\hline Ganho de peso (g/dia) & 198 & 197 & 201 & 206 & 200 & 202 & 17,01 \\
\hline \multicolumn{8}{|l|}{ Peso da leitegada (kg): } \\
\hline Ao nascer & 14,75 & 16,84 & 15,72 & 17,46 & 15,80 & 17,28 & 23,28 \\
\hline Ao desmame & 49,94 & 55,33 & 52,06 & 57,33 & 50,67 & 56,39 & 20,39 \\
\hline
\end{tabular}

${ }^{1}$ Relação aminoácido/lisina com base na recomendação de Rostagno et al. (2005). 
Dourmad et al. (1998). De acordo com Jones \& Stahly (1999a), a restrição de aminoácidos durante a lactação aumenta a mobilização de proteína corporal e reduz a produção de leite. Dessa forma, considerando que o leite é a principal fonte de nutrientes disponível para o leitão durante a lactação, a sua redução pode ter reflexos diretos sobre o ganho de peso dos leitões e da leitegada. Portanto, no presente estudo não se verificou $(\mathrm{P}>0,05)$ efeito dos tratamentos sobre o ganho de peso dos leitões e da leitegada, uma vez que não houve redução na produção de leite.

O fato de os aminoácidos sulfurados, treonina, triptofano e valina poderem interferir negativamente na produção de leite quando limitantes na ração (Touchette et al., 1998) e de a produção de leite ter sido mantida em todos os animais sem variação significativa na mobilização de proteína e gordura corporal das porcas possibilita inferir que as relações dos aminoácidos metionina + cistina, treonina, triptofano e valina com a lisina na base digestível propostas, na proteína ideal (Rostagno et al., 2005), para porcas em lactação estão adequadas, visto que o consumo de lisina digestível não variou entre as dietas.

\section{Conclusões}

As relações dos aminoácidos metionina + cistina (54\%), treonina (64\%), triptofano (19\%) e valina (78\%) digestíveis com a lisina digestível atendem as exigências de porcas em lactação para melhores desempenhos produtivo e reprodutivo.

\section{Referências}

ABREU, M.L.T.; DONZELE, J.L.; MOITA, A.M.S. Nutrição para matrizes suínas de alta performance. In: CONGRESSO LATINO AMERICANO DE SUINOCULTURA, 3., Foz do Inguaçu. Anais... Foz do Iguaçu, p.129-139, 2005.

BLACK, J.L.; MULLAN, B.P.; LORSCHY, M.L. et al. Lactation in the sow during heat stress. Livestock Production Science, v.35, p.153-170, 1993.

CLOWES, E.J.; AHERNE, F.X.; FOXCROFT, G.R. et al. Selective protein loss in lactation sows is associated with reduced litter growth and ovarian function. Journal of Animal Science, v.81, p.753-764, 2003.

COTA, T.S.; DONZELE, J.L.; OLIVEIRA, R.F.M. et al. Níveis de lisina em ração de lactação para fêmeas suínas primíparas. Revista Brasileira de Zootecnia, v.32, p.115-122, 2003.

DE BRAGANÇA, M.M.; MOUNIER, M.; PRUNIER, A. Does feed restriction mimic the effects of increased ambient temperature in lactating sows? Journal of Animal Science, v.76, p.2017-2024, 1998.

DOURMAD, J.Y.; ETIENNE, M.; NOBLET, J. Effect of protein and lysine supply on performance, nitrogen balance, and body composition changes of sows during lactation. Journal of Animal Science, v.76, p.542-550, 1998.

JOHNSTON, L.J.; PETTIGREW, J.E.; RUST, J.W. Response of maternal-line sows to dietary protein concentration during lactation. Journal of Animal Science, v.71, p.2152-2156, 1993.

JONES, D.B.; STAHLY, T.S. Impact of amino acid nutrition during lactation on body nutrient mobilization and milk nutrient output in primiparous sows. Journal of Animal Science, v.77, p.1513-1522, 1999a.

JONES, D.B.; STAHLY, T.S. Impact of amino acid nutrition during lactation on luteinizing hormone secretion and return to estrus in primiparous sows. Journal of Animal Science, v.77, p.1523-1531, 1999b.

KIM, S.W.; BAKER, D.H.; EASTER, R.A. Dynamic ideal protein and limiting amino acids for lactating sows: Impact of amino acid mobilization. Journal of Animal Science, v.79, p.2356-2366, 2001.

KIM, S.W.; OSAKA, L.; HURLEY, W.L. et al. Mamary gland growth as influenced by litter size in lactating sows: impact on lysine requirement. Journal of Animal Science, v.77, p.3316-3321, 1999.

KING, R.H. Nutritional anoestrus in young sows. Pig News Information, v.8, p.15-22, 1987

KING, R.H.; DUNKIN, A.C. The effect of nutrition on the reproductive performance of first-litter sows. Animal Production, v.43, p.319-325, 1986.

MULLAN, B.P.; WILLIANS, I.H. The chemical composition of sows during their first lactation. Animal Production, v.51, p.375-387, 1990.

NOBLET, J.; ETIENNE, M. Estimation of sow milk nutrient output. Journal Animal of Science, v.67, p.3352-3359, 1989.

NOBLET, J.; ETIENNE, M.; DOURMAD, J.Y. Energetic efficiency of milk production. In: VERSTEGEN, M.W.A.; MOUGHAN, P.J.; SCHRAMA, J.W. (Eds.) The lactating sow. Wageningen: Wageningen Press, p.113-130, 1998.

OLIVEIRA, V.A.F.; DONZELE, J.L.; ABREU, M.L.T. Treonina digestível em rações para matrizes suínas em lactação. Revista Brasileira de Zootecnia, v.37, p.112-110, 2008.

RICHERT, B.T.; GOODBAND, R.D.; TOKACH, M.D. et al. Increasing valine, isoleucine, and total branched-chain amino acids for lactation sows. Journal of Animal Science, v.75, p.2117-2128, 1997.

ROSTAGNO, H.S.; ALBINO, L.F.T.; DONZELE, J.L. et al. Composição de alimentos e exigências nutricionais de aves e suínos: Tabelas Brasileiras. Viçosa, MG: UFV, 2005. p.186.

THAKER, M.Y.C.; BILKEI, G. Lactation weight loss influences subsequent reproductive performance of sows. Animal Reproduction Science, v.88, p.309-318, 2005.

TOKACH, M.D.; PETTIGREW, J.E.; DIAL, G.G. et al. Characterization of luteinizing hormone secretion in the primiparous sows: relationship to blood metabolites and returnto-estrus. Journal of Animal Science, v.70, p.2195, 1992.

TOUCHETTE, K.J.; ALLEE, G.L.; NEWCOMB, M.D. et al. The lysine requirement of lactating primiparous sows. Journal of Animal Science, v.76, p.1091-1097, 1998.

UNIVERSIDADE FEDERAL DE VIÇOSA - UFV. SAEG - Sistemas de Análises Estatísticas e Genéticas. Versão 8.0. Viçosa, MG, 2000. 141p.

WHITTEMORE, C.T.; YANG, H. Physical and chemical composition of the body of breeding sows with differing body subcutaneous fat depth at parturition, differing nutrition during lactation and differing litter size. Animal Production, v.48, p.203-202, 1989 